DOI:

УДК 628.32:004

В.С. Авер'янов, к.т.н., доцент, averynov@ukr.net

Д.3. Шматко, к.т.н., доцент, zombizon@yandex.ua

O.O. Сасов, к.т.н., доцент, sasov@ukr.net

О.Г. Чернета, к.т.н., доцент, ocherneta@gmail.com

Дніпровський державний технічний університет, м. Кам’янське

\title{
МАТЕМАТИЧНЕ МОДЕЛЮВАННЯ ПРОЦЕСУ ОЧИЩЕННЯ СТІЧНИХ ВОД ПРИ ВИКОРИСТАННІ ПАПЕРОВИХ ФІЛЬТРУВАЛЬНИХ МАТЕРІАЛІВ
}

Розглянутий процес фільтрування рідини в безкамерних установках з використанням паперових фільтрувальних матеріалів, а також залежність продуктивності фільтрувальної установки на різних технологічних режимах роботи установки. Встановлено характер залежності продуктивності процесу фільтрування від витрати очищуваної води,концентрації механічних домішок, товщини та щільності паперових фільтрувальних матеріалів. Отримані математичні моделі представлені поліномом другого порядку та дозволяють враховувати не тільки технічні характеристики, але і вплив характеристики паперових фільтрувальних матеріалів на продуктивність прочесу фільтрування очищуваної води. Запропонована математична модель дозволить визначити та підібрати необхідні характеристики паперових фільтрувальних матеріалів та геометричні параметри соплової групи для забезпечення максимальної продуктивності фільтрування. При виборі паперових фільтрувальних матеріалів із необхідними заданими властивостями та їх використанні обов'язково потрібно враховувати вплив набухання целюлозних волокон на їх виробничі характеристики, що має знайти необхідне відображення в технологічних регламентах експлуатащії пристроїв на їх основі.

Ключові слова: математичні моделі; планування експерименту очищення; паперові фільтрувальні матеріали; продуктивність.

The process of filtering liquid in tubeless installations using paper filter materials, as well as the dependence of the performance of the filter installation on different technological modes of the installation. The nature of the dependence of the filtration process on the flow rate of the purified water, the concentration of mechanical impurities, the thickness and the density of the paper filter materials has been established. The mathematical models obtained are represented by a second-order polynomial and allow to take into account not only the technical characteristics, but also the influence of the characteristics of paper filter materials on the performance of the filtered water filtration process. The proposed mathematical model will allow to determine and select the necessary characteristics of paper filter materials and geometric parameters of the nozzle group for maximum filtration performance. When selecting paper filter materials with the required set properties and their use, it is necessary to take into account the influence of the swelling of the cellulose fibers on their production characteristics, which should be reflected in the technological regulations for the operation of devices based on them.

Keywords: mathematical models; design of purification experiment; paper filter materials; productivity.

\section{Постановка проблеми}

В даний час методика розрахунку продуктивності фільтрувальних установок з безкамерний фільтруванням, а також визначення опору фільтрувальної перегородки, що виникає при проходженні через неї вимагає уточнення. У фільтрувальних пристроях, заснованих на використанні енергії затопленої або вільної струменя рідини, процес фільтрування проводиться з закупоркою пір фільтрувальної перегородки. Осад з твердих частинок на поверхні фільтрувальної перегородки при досить великої продуктивності очищення практично не утворюється. 
Застосування паперових фільтрувальних елементів у спеціальних пристроях, які забезпечують підтримання найвищої чистоти очищуваного середовища, обмежується ресурсом, міцністю, фільтраційними, сорбційними та іншими властивостями [1].

У зв'язку з необхідністю забезпечення найвищої чистоти води у фармацевтичній та електронній промисловості, а також можливістю використання паперових фільтрувальних матеріалів (ПФМ) і для очищення повітря на атомних електростанціях; у фільтровентиляційних системах сховищ, лікувальних установ, операційних, виробничих цехах (бродильні відділення) харчової та фармацевтичної промисловості тощо, виникає потреба у математичній моделі за допомогою якої можна було б встановити композиційний склад ПФМ, який надавав би зразкам потрібні властивості, необхідні в кожній конкретній ситуації [2].

\section{Аналіз останніх досліджень і публікацій}

Забруднення води є одним з основних факторів ризику для здоров'я, пов'язаних із навколишнім середовищем, що зумовлює потребу в належній її очистці перед використанням [3]. Актуальною стає потреба у високоефективних сорбентах, що характеризуються одночасною бактерицидною дією, наприклад, для очищення питної води, води для фармацевтичної промисловості, або їх застосування у медичній практиці [4].

При фільтруванні різних середовищ мікробіологічні забруднення сорбуються матеріалами як з гранульованою, так і волокнистою структурою [5]. При цьому не лише зберігається життєздатність, а і йде розмноження мікроорганізмів [6]. В результаті відбувається біообростання сорбентів і викид продуктів життедіяльності мікроорганізмів, а інколи і самих мікроорганізмів, у фільтрат [7]. Запобігання біообростанню фільтрувальних матеріалів та, зокрема, сорбентів залишається актуальною проблемою [8].

Існують матеріали, отримані обробкою носія солями металу, наприклад, розчином солі срібла. Бактерицидна добавка знаходиться на поверхні цих матеріалів або у вигляді ізольованих іонів, або у вигляді комплексних з'єднань. Ці матеріали не забезпечують необхідного рівня ефективності очищення від колоїдних часток і вірусів, розмір яких знаходиться в межах $10-30$ нм [9]. До недоліків додається і те, що бактерицидні властивості використовуваних матеріалів визначаються іонами бактерицидних компонентів, що переходять в процесі фільтрування в середовище, що очищається, таким чином, забруднюючи його [10]. Для забезпечення тривалості збереження бактерицидних властивостей цих матеріалів потрібне просочення носіїв концентрованими розчинами солей металів. Відомо, що при певних підвищених концентраціях бактерицидних іонів металів вони отруйні для людини [11].

\section{Формування мети дослідження}

Метою досліджень $\epsilon$ оцінка властивостей створених модернізованих матеріалів паперових фільтрувальних для розробки математичних моделей, які б дозволили визначити та підібрати необхідні характеристики паперових фільтрувальних матеріалів та геометричні параметри соплової групи для забезпечення максимальної продуктивності фільтрування.

Для досягнення поставленої мети були сформульовані такі завдання:

- визначити залежність фільтрувальних та сорбційних здатностей досліджуваних зразків матеріалів паперових фільтрувальних від їх характеристик та геометричних параметрів соплової групи;

- розробити математичні моделі, які дозволяли б визначити необхідні характеристики паперових фільтрувальних матеріалів для забезпечення максимальної продуктивності фільтрування.

\section{Виклад основного матеріалу}

Обсяг очищеної рідини, що отримується протягом певного проміжку часу з одиниці поверхні фільтрувальної перегородки, прямо пропорційний різниці тисків і обернено пропорційний в'язкості рідини і загального опору осаду і фільтрувальної перегородки [12]:

$$
\frac{d V}{\omega_{1} \cdot d \tau}=\frac{\Delta p}{\mu \cdot\left(R_{o c}+R_{\hat{o} . i}\right)},
$$


де $V$ - об'єм очищеної рідини, м ${ }^{3} ; \omega_{1}$ - площа поверхні фільтрувальної перегородки, $\mathrm{m}^{2} ; \tau-$ тривалість фільтрування, с; $\Delta p$ - різниця тисків, Па; $\mu$ - коефіцієнт динамічної в'язкості очищеної рідини, $\mathrm{H} \cdot \mathrm{c}^{\mathrm{m}} \mathrm{m}^{2} ; R_{o c}$ - опір шару осаду, $\mathrm{m}^{-1} ; R_{\phi . n}$ - опір фільтрувальної перегородки, $\mathrm{M}^{-1}$.

Розглянемо процес фільтрування рідини в установці безкамерного фільтрування. Схема процесу фільтрування представлена на рис. 1. [13]

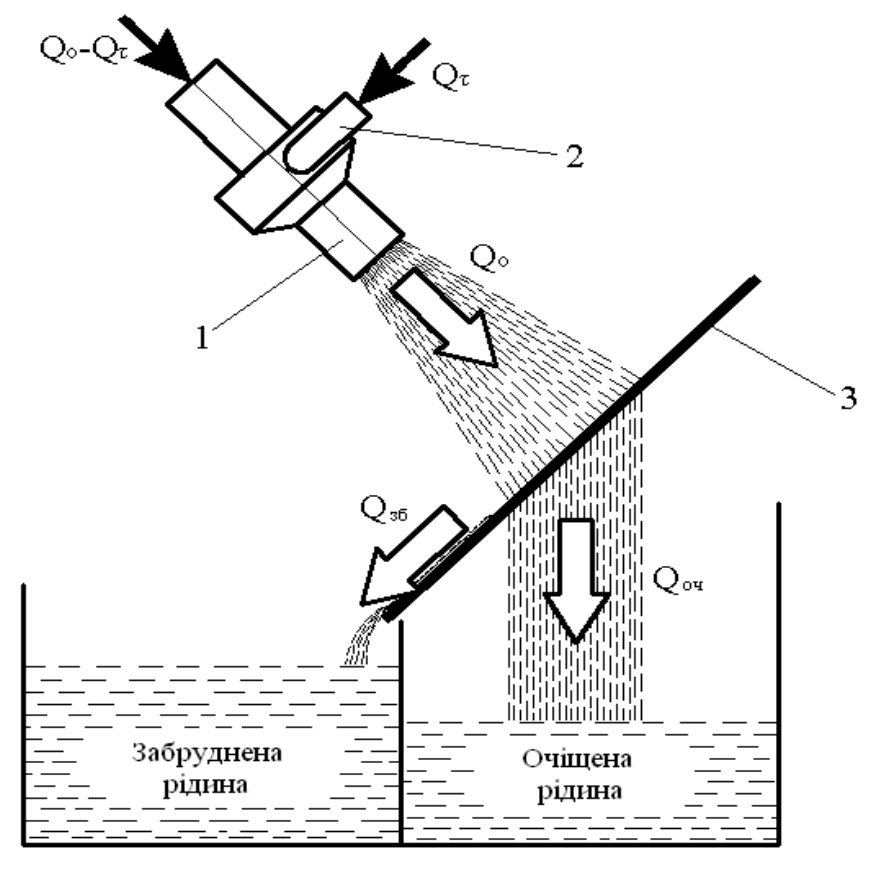

Puc. 1. Схема процесу фільтрування: 1 - форсунка; 2 - тангенціально врізаний патрубок; 3 - фільтрувальна перегородка; $Q_{3 a а}$ - загальна витрата рідини; $Q_{o ч}$ - витрата очищеної рідини; $Q_{3 \sigma}$ - витрата скидання рідини

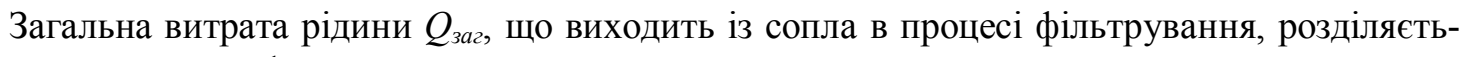
ся, як показано на рис. 1, на два потоки:

$$
Q_{3 a 2}=Q_{o ч}+Q_{30}
$$

де $Q_{o 4}$ - витрата очищеної рідини, м³/с; $Q_{3 \sigma}$ - витрата скидання забрудненої рідини, $\mathrm{m}^{3} / \mathrm{c}$.

Величина $Q_{o ч}$ визначає продуктивність фільтрувальної установки, яка залежить від геометричних параметрів установки, властивостей рідини і матеріалу фільтрувальної перегородки. Тому необхідно визначити залежність продуктивності установки від характеристики фільтрувального матеріалу.

Величина очищеної рідини залежить: від витрати забрудненої рідини через сопло $Q_{3 а г ;}$; від товщини $\delta$ та щільності $\rho$ фільтрувального матеріалу; від вхідної концентрації механічних домішок $k_{6 x}$.

Для побудови математичної моделі залежності продуктивності фільтрувальної установки від вищенаведених факторів у вигляді полінома другого порядку застосовувалися методи планування експерименту, а саме, повний факторний експеримент. Рівні варіювання факторів представлені в табл. 1.

Експериментальні дослідження проводилися за допомогою ємності певного обсягу. Величину очищеної рідини вимірювали на відповідних технологічних режимах роботи установки. В результаті обробки експериментальних даних були отримані оцінки впливу факторів і взаємодій чинників на досліджуваний параметр $Q_{\text {оч}}$. 
Таблиия 1. Рівні варіювання факторів

\begin{tabular}{|l|c|c|c|c|c|c|}
\hline \multicolumn{1}{|c|}{ Фактори } & $\begin{array}{c}\text { Позначення } \\
\text { факторів }\end{array}$ & $x_{i}^{*}=-1,68$ & $x_{i}=-1$ & $x_{i}=0$ & $x_{i}=1$ & $x_{i} *=1,68$ \\
\hline $\begin{array}{l}\text { Кількість фільтрованої } \\
\text { рідини } Q_{\text {заг }} \mathrm{M}^{3} / \mathrm{c}\end{array}$ & $x_{1}$ & 0,66 & 1 & 1,5 & 2 & 2,34 \\
\hline $\begin{array}{l}\text { Товщина паперового фільтру } \\
\delta, \text { мкм }\end{array}$ & $x_{2}$ & 400 & 420 & 450 & 480 & 500 \\
\hline $\begin{array}{l}\text { Щільність паперового } \\
\text { фільтру } \rho, \text { гсм }\end{array}$ & $x_{3}$ & 0,4 & 0,42 & 0,45 & 0,48 & 0,5 \\
\hline $\begin{array}{l}\text { Вхідна концентрація } \\
\text { механічних домішок } k_{6 x}, \text { г/л }\end{array}$ & $x_{4}$ & 2 & 5 & 10 & 15 & 18 \\
\hline
\end{tabular}

Матриця плану та відповідні отримані результати експерименту наведено в табл. 2.

Таблиия 2. Матриця планування і результати дослідження

\begin{tabular}{|l|c|c|c|c|c|}
\hline \multirow{2}{*}{ № } & \multicolumn{5}{|c|}{ Кодоване значення факторів в експерименті } \\
\cline { 2 - 6 } & $\widetilde{x}_{1}$ & $\widetilde{x}_{2}$ & $\widetilde{x}_{3}$ & $\widetilde{x}_{4}$ & $y$ \\
\hline 1 & -1 & -1 & -1 & 1 & 0,35 \\
\hline 2 & 1 & -1 & -1 & 1 & 0,65 \\
\hline 3 & -1 & 1 & -1 & 1 & 0,42 \\
\hline 4 & 1 & 1 & -1 & 1 & 0,55 \\
\hline 5 & -1 & -1 & 1 & 1 & 0,52 \\
\hline 6 & 1 & -1 & 1 & 1 & 0,58 \\
\hline 7 & -1 & 1 & 1 & 1 & 0,3 \\
\hline 8 & 1 & 1 & 1 & 1 & 0,46 \\
\hline 9 & -1 & -1 & -1 & -1 & 0,53 \\
\hline 10 & 1 & -1 & -1 & -1 & 0,85 \\
\hline 11 & -1 & 1 & -1 & -1 & 0,76 \\
\hline 12 & 1 & 1 & -1 & -1 & 0,62 \\
\hline 13 & -1 & -1 & 1 & -1 & 0,74 \\
\hline 14 & 1 & -1 & 1 & -1 & 0,72 \\
\hline 15 & -1 & 1 & 1 & -1 & 0,67 \\
\hline 16 & 1 & 1 & 1 & -1 & 0,8 \\
\hline 17 & 1,68 & 0 & 0 & 0 & 1,1 \\
\hline 18 & $-1,68$ & 0 & 0 & 0 & 0,25 \\
\hline 19 & 0 & 1,68 & 0 & 0 & 0,58 \\
\hline 20 & 0 & $-1,68$ & 0 & 0 & 0,83 \\
\hline 21 & 0 & 0 & 1,68 & 0 & 0,42 \\
\hline 22 & 0 & 0 & $-1,68$ & 0 & 0,76 \\
\hline 23 & 0 & 0 & 0 & 1,68 & 0,38 \\
\hline 24 & 0 & 0 & 0 & $-1,68$ & 0,78 \\
\hline 25 & 0 & 0 & 0 & 0 & 0,7 \\
\hline 26 & 0 & 0 & 0 & 0 & 0,68 \\
\hline 27 & 0 & 0 & 0 & 0 & 0,71 \\
\hline 28 & 0 & 0 & 0 & 0 & 0,72 \\
\hline 29 & 0 & 0 & 0 & 0 & 0,7 \\
\hline 30 & 0 & 0 & 0 & 0 & 0,69 \\
\hline 31 & 0 & 0 & 0 & 0 & 0,7 \\
\hline
\end{tabular}


Для переміщення до точки оптимуму використовувалася математична модель виду:

$$
y=f\left(x_{1}, x_{2}, \ldots, x_{k}\right)
$$

де $x_{1}, \ldots, x_{k}$ - фактори залежностей.

В даному випадку математична модель для повного чотирьох факторного експерименту 3 ефектом взаємодії має вигляд [14]:

$$
\begin{aligned}
& y=b_{0}+b_{1} \cdot x_{1}+b_{2} \cdot x_{2}+b_{3} \cdot x_{3}+b_{4} \cdot x_{4}+b_{12} \cdot x_{1} \cdot x_{2}+b_{13} \cdot x_{1} \cdot x_{3}+b_{14} \cdot x_{1} \cdot x_{4}+b_{23} \cdot x_{2} \cdot x_{3}+b_{24} \cdot x_{2} \cdot x_{4}+ \\
& +b_{34} \cdot x_{3} \cdot x_{4}+b_{123} \cdot x_{1} \cdot x_{2} \cdot x_{3}+b_{124} \cdot x_{1} \cdot x_{2} \cdot x_{4}+b_{134} \cdot x_{1} \cdot x_{3} \cdot x_{4}+b_{234} \cdot x_{2} \cdot x_{3} \cdot x_{4}+b_{1234} \cdot x_{1} \cdot x_{2} \cdot x_{3} \cdot x_{4}+ \\
& +b_{11} \cdot x_{1}^{2}+b_{22} \cdot x_{2}^{2}+b_{33} \cdot x_{3}^{2}+b_{44} \cdot x_{4}^{2} .
\end{aligned}
$$

Дисперсію $S_{y}^{2}$ відтворюваності визначаємо по результатам досліджень в центрі плану. Дисперсії, що характеризують помилки в визначенні коефіцієнтів рівняння регресії, згідно [14] при $\kappa=4$ становлять:

$$
S^{2}\left\{b_{0}\right\}=0,5833 ; S^{2}\left\{b_{i}\right\}=0,2563 ; S^{2}\left\{b_{i l}\right\}=0,1375 ; S^{2}\left\{b_{i i}\right\}=0,0433 .
$$

При перевірці коефіцієнтів за критерієм Ст'юдента (при 5 \%-му рівні значимості та числі ступеню свободи $f=5$ ) встановлено, що всі коефіцієнти значимі і включено до моделі (2).

Перевірка гіпотези адекватності моделі (4) за критерієм Фішера при 5 \%-му рівні значущості і числах ступенів свободи дисперсії адекватності $f_{a d}=N-k-\left(n_{0}-1\right)=31-14-(7-1)=11$ і дисперсії відтворюваності $f_{y}=n_{0}-1=7-1=6$ показала, що отримані моделі адекватні, оскільки розрахункове значення критерію менше табличного $F_{c a l}=2,54<F_{\dot{O}}(0,05 ; 11 ; 6)=3,09$.

Після визначення коефіцієнтів і деяких математичних перетворень отримаємо математичну залежність для визначення продуктивності фільтрувальної установки від вищенаведених факторів:

$$
\begin{aligned}
& Q_{o u}=-12,8-3,4 \cdot Q_{3 a 2}+0,04 \cdot \delta+70,4 \cdot \rho+0,12 \cdot k_{b x}+0,011 \cdot Q_{3 a 2} \cdot \delta-4 \cdot Q_{3 a 2} \cdot \rho-0,12 \cdot \delta \cdot \rho- \\
& -7 \cdot 10^{-5} \cdot \delta \cdot k_{b x}-0,2 \cdot \rho \cdot k_{B x}+0,01 \cdot Q_{3 a z}{ }^{2}+0,01 \cdot \delta^{2}+0,034 \cdot \rho^{2}+0,34 \cdot k_{b x}{ }^{2} .
\end{aligned}
$$

За допомогою математичної моделі (4) можна визначити продуктивність фільтрування та підібрати необхідні характеристики матеріалів паперових фільтрувальних для вирішення відповідних завдань.

\section{Висновки}

Проведені дослідження та розроблені математичні моделі дозволяють визначити продуктивність процесу фільтрування від витрати фільтрованої води, товщини та щільності паперових фільтрувальних матеріалів, вхідної концентрації механічних домішок. Запропоновані математичні моделі дозволяють також визначити необхідні технічні характеристики паперових фільтрувальних матеріалів.

Встановлено, що зразки із найвищою щільністю та найменшою товщиною та зразки із найменшою щільністю та найбільшою товщиною мають більшу фільтраційну та сорбційну здатність, ніж зразки із середніми значеннями щільності та товщини. Це дозволяє припустити, що на фільтрувальні та сорбційні характеристики впливає також і просторове розташування волокнистих сорбентів у фільтруючому шарі ПФМ, що може бути пов'язане із феноменом набухання целюлозних волокон у вологому стані.

При виборі паперових фільтрувальних матеріалів із необхідними заданими властивостями та їх використанні обов'язково потрібно враховувати вплив набухання целюлозних волокон на їх виробничі характеристики, що має знайти необхідне відображення в технологічних регламентах експлуатації пристроїв на їх основі.

\section{Список використаної літератури}

1. Загороднюк К. Ю., Гринзовський А. М., Коробочка О. М., Авер'янов В. С. Гігієнічна оцінка модифікованих паперових фільтрувальних матеріалів на основі сульфітної віскозної целюлози. Актуальні питання громадського здоров'я та екологічної безпеки Украӥни. Зб. тез доп. наук.-практ. конф. Київ. 2018. С. 308-310. 
2. Averyanov V., Zahorodniuk K., Voitsekhovsky V., Korobochka A., Hrynzovskyi A. Development of modernized filtering paper materials for water treatment, assessment of their properties. Eastern European Journal of Enterprise Technologies. Ecology. Kharkiv, 2019. - 1/10 (97). P.6-13. DOI:10.15587/1729-4061.2019.156534

3. Zagorodniuk K., Bardov V., Omelchuk S., Zagorodniuk Yu. Ukraine's population water supply: nowadays realities and ecologically-hygienic assessment of possible ways of branch's development. The Unity of science. 2015. Issue 4. P. 193-202.

4. Gardi I., Mishael Y. G. Designing a regenerable stimuli-responsive grafted polymer-clay sorbent for filtration of water pollutants. Science and Technology of Advanced Materials. 2018. Vol. 19, Issue 1. P. 588-598. doi: https://doi.org/10.1080/14686996.2018.1499381

5. Загороднюк Ю. В., Широбоков В. П., Войцеховский В. Г. Оцінка ефективності вилучення вірусів із питної води матеріалами паперовими фільтрувальними на основі модифікованих целюлоз та бентонітових глин. Чиста вода. Фундаментальні, прикладні та промислові аспекти. Матеріали V Міжнар. наук.-техн. конф. Київ: НМУ, 2017. С. 112-114.

6. Forouzanfar M. H., Alexander L., Anderson H. R., Bachman V. Global, regional, and national comparative risk assessment of 79 behavioural, environmental and occupational, and metabolic risks or clusters of risks in 188 countries, 1990-2013: a systematic analysis for the Global Burden of Disease Study 2013. The Lancet. 2015. Vol. 386, Issue 10010. P. 2287-2323. doi: https://doi.org/10.1016/s0140-6736(15)00128-2

7. Bcheraoui C., Kamath A., Dansereau E., Palmisano E. Results-based aid with lasting effects: sustainability in the Salud Mesoamérica Initiative. Globalization and Health. 2018. Vol. 14, Issue 1. doi: https://doi.org/10.1186/s12992-018-0418-x

8. Khalil I., Troeger C., Blacker B., Rao P., Brown A. Morbidity and mortality due to shigella and enterotoxigenic Escherichia coli diarrhoea: the Global Burden of Disease Study 1990-2016. The Lancet Infectious Diseases. 2018. Vol. 18, Issue 11. P. 1229-1240. doi: https://doi.org/10.1016/s1473-3099(18)30475-4

9. Rajaeian B., Allard S., Joll C., Heitz A. Effect of preconditioning on silver leaching and bromide removal properties of silver-impregnated activated carbon (SIAC). Water Research. 2018. Vol. 138. P. 152-159. doi: https://doi.org/10.1016/j.watres.2018.03.026

10. Medici S., Peana M., Crisponi G., Nurchi V. Silver coordination compounds: A new horizon in medicine. Coordination Chemistry Reviews. 2016. Vol. 327-328. P. 349-359. doi: https://doi.org/10.1016/j.ccr.2016.05.015

11. Chekman I. S. Pharmacological Properties of Nanometals (Silver, Copper, Iron). Nauka ta innovacii. 2015. Vol. 11, Issue 1. P. 72-77. doi: https://doi.org/10.15407/scin11.01.072

12. Коробочка А.Н., Тихонцов А.М., Брылев Е.А. Очистка технологических сред при обработке металлов резанием.- Воронеж: Изд-во ВГУ, 1992. 128c.

13. Авер'янов В.С., Олійник О.Л., Коробочка О.М. Установка для фільтрування рідини. Патент України на корисну модель. № 39634. 10.03.2009. Бюл. № 5/2009.

14. Шкляр В. Н. Планирование эксперимента и обработка результатов. Томск: ТПУ, 2010. 90 с.

\section{MATHEMATICAL MODELING OF THE WASTE WATER TREATMENT PROCESS WHEN USING PAPER FILTER MATERIALS Averyanov V., Shmatko D., Sasov A., Cherneta O.}

\footnotetext{
Abstract

The application of filtering paper elements in special devices that ensure the maintenance of the highest purity of the treated medium is limited to resource, durability, filtration, sorption and other properties.

In connection with the need to ensure the highest purity of water in pharmaceutical and electronic industries, as well as the possibility of using the filtering paper materials for cleaning the air
} 
at nuclear power plants; in filter-ventilating systems of refuges, medical establishments, operational, production workshops (fermentation departments) of the food and pharmaceutical industries, etc., there is a need for a mathematical model, with the help of which it would be possible to establish the compositional structure of the filtering paper materials, which would provide the samples with the required properties needed in each particular situation.

The conducted researches and the developed mathematical models allow to determine the performance of the filtration process from the flow of filtered water, the thickness and density of paper filter materials, the input concentration of mechanical impurities. The proposed mathematical models also allow you to determine the required technical characteristics of paper filter materials.

It was found that the samples with the highest density and the lowest thickness and the samples with the lowest density and the highest thickness had a higher filtration and sorption capacity than the samples with the average values of the density and thickness. This suggests that the filtering and sorption characteristics are also influenced by the spatial arrangement of the fibrous sorbents in the filtering paper materials filter layer, which may be related to the phenomenon of cellulose fiber swelling in the wet state.

When selecting paper filter materials with the required set properties and their use, it is necessary to take into account the influence of the swelling of the cellulose fibers on their production characteristics, which should be reflected in the technological regulations for the operation of devices based on them.

\section{References}

[1] Zahorodniuk, K., Hrynzovskyi, A., Korobochka, O., Averianov, V. (2018). Hihienichna otsinka modyfikovanykh paperovykh filtruvalnykh materialiv na osnovi sulfitnoi viskoznoi tseliulozy [Hygienic evaluation of modified paper filter materials based on sulphite viscose cellulose]. $A k$ tualni pytannia hromadskoho zdorovia ta ekolohichnoi bezpeky Ukrainy. Kyiv, 308-310 [in Ukrainian].

[2] Averyanov V., Zahorodniuk K., Voitsekhovsky V., Korobochka A., Hrynzovskyi A. (2019). Development of modernized filtering paper materials for water treatment, assessment of their properties. Eastern European Journal of Enterprise Technologies. Ecology. 1/10 (97). 6-13. DOI:10.15587/1729-4061.2019.156534

[3] Zagorodniuk, K., Bardov, V., Omelchuk, S., Zagorodniuk, Yu., Pelo, I. (2015). Ukraine's population water supply: nowadays realities and ecologically-hygienic assessment of possible ways of branch's development. The Unity of science. 4, 193-202 [in Ukrainian].

[4] Gardi, I., Mishael, Y. G. (2018). Designing a regenerable stimuli-responsive grafted polymer-clay sorbent for filtration of water pollutants. Science and Technology of Advanced Materials, 19 (1), 588-598. doi: https://doi.org/10.1080/14686996.2018.1499381

[5] Zahorodniuk, Yu., Shyrobokov, V., Voitsekhovskyi, V. (2017). Otsinka efektyvnosti vyluchennia virusiv iz pytnoi vody materialamy paperovymy filtruvalnymy na osnovi modyfikovanykh tseliuloz ta bentonitovykh hlyn [Evaluation of the Efficiency of Extracting Viruses from Drinking Water with Paper Filter Materials Based on Modified Celluloses and Bentonite Clays]. Chysta voda. Fundamentalni, prykladni ta promyslovi aspekty. Kyiv: NMU, 112-114 [in Ukrainian].

[6] Forouzanfar, M., Alexander, L., Anderson, H., Bachman, V. (2015). Global, regional, and national comparative risk assessment of 79 behavioural, environmental and occupational, and metabolic risks or clusters of risks in 188 countries, 1990-2013: a systematic analysis for the Global Burden of Disease Study 2013. The Lancet, 386 (10010), 2287-2323. doi: https://doi.org/10.1016/s01406736(15)00128-2

[7] Bcheraoui, C., Kamath, A., Dansereau, E., Palmisano, E. (2018). Results-based aid with lasting effects: sustainability in the Salud Mesoamérica Initiative. Globalization and Health, 14 (1). doi: https://doi.org/10.1186/s12992-018-0418-x

[8] Khalil, I., Troeger, C., Blacker, B., Rao, P., Brown, A. (2018). Morbidity and mortality due to shigella and enterotoxigenic Escherichia coli diarrhoea: the Global Burden of Disease Study 1990-2016. The Lancet Infectious Diseases, 18 (11), 1229-1240. doi: 
https://doi.org/10.1016/s1473-3099(18)30475-4

[9] Rajaeian, B., Allard, S., Joll, C., Heitz, A. (2018). Effect of preconditioning on silver leaching and bromide removal properties of silver-impregnated activated carbon (SIAC). Water Research, 138, 152-159. doi: https://doi.org/10.1016/j.watres.2018.03.026

[10] Medici, S., Peana, M., Crisponi, G., Nurchi, V. (2016). Silver coordination compounds: A new horizon in medicine. Coordination Chemistry Reviews, 327-328, 349-359. doi: https://doi.org/10.1016/j.ccr.2016.05.015

[11] Chekman, I. (2015). Pharmacological Properties of Nanometals (Silver, Copper, Iron). Nauka Ta Innovacii, 11 (1), 72-77. doi: https://doi.org/10.15407/scin11.01.072

[12] Korobochka, A., Tikhonczov, A., Brylev, E. (1992). Ochistka tekhnologicheskikh sred pri obrabotke metallov rezaniem [Cleaning of technological environments during metal cutting]. Voronezh: Izd-vo VGU [in Russian].

[13] Averyanov, V., Olijnik, O., Korobochka, O. (2009). Ustanovka dlya filtruvannya ridini. Patent Ukrayini na korisnu model [Installation for filtering liquid. Patent of Ukraine for utility model]. \# 39634. Byul. \# 5/2009 [in Ukrainian].

[14] Shklyar, V. (2010). Planirovanie eksperimenta i obrabotka rezultatov [Experiment planning and results processing]. Tomsk: TPU, [in Russian]. 